\title{
Butane hash oil and dabbing: insights into use, amateur production techniques, and potential harm mitigation
}

REVIEW

\author{
Ihsan Al-Zouabi' \\ John M Stogner' \\ Bryan Lee Miller ${ }^{2}$ \\ Elizabeth S Lane' \\ 'Department of Criminal Justice and \\ Criminology, University of North \\ Carolina at Charlotte, Charlotte, NC \\ 28223-000I, USA; ${ }^{2}$ Department of \\ Sociology, Anthropology and Criminal \\ Justice, Clemson University, Clemson, \\ SC 2963I, USA
}

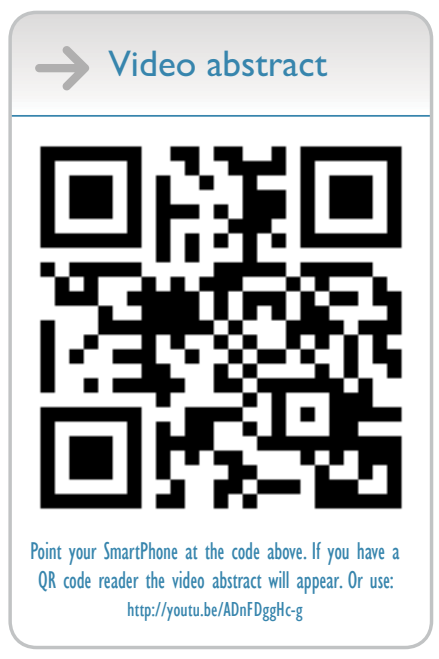

Correspondence: John M Stogner Department of Criminal Justice and Criminology, University of North

Carolina at Charlotte, 920I University City Blvd., Charlotte, NC 28223-000I, USA

Tel + I 9193576836

Email johnstogner@uncc.edu
This article was published in the following Dove Press journal: Substance Abuse and Rehabilitation

\begin{abstract}
The use of marijuana concentrates has escalated in recent years with butane extracts appearing particularly popular. The administration of butane hash oil, colloquially referred to as "dabbing," is distinct from traditional flower cannabis usage due to the THC content of samples and the presence of impurities such as unpurged butane. While this may confer heightened risk to the user, additional significant concerns are tied to fires and explosions. Using butane as a solvent in amateur "blasting" methods may result in a flammable vapor pooling in enclosed spaces and igniting when exposed to a spark. As research on butane extract users, amateur production techniques, health risks, and legality is in its infancy, we explored existing studies on the topic to create a review of substantiated knowledge related to THC extracted using butane. The resulting assessment centers on three areas: 1) dab users including both recreational users and medical marijuana patients; 2) butane extraction techniques including illicit amateur open methods and the safer closed-loop system employed in medicinal/recreational states; and 3) risks, both related to fires and legality. We follow the presentation of this material with a summary of the (mis)information reaching the public in print and online sources so that public educational campaigns can focus on dispelling the inaccuracies and false notions of safety that may be tied to amateur production.
\end{abstract}

Keywords: butane hash oil, dabbing, dabs, marijuana, marijuana concentrates, blasting

\section{Butane hash oil - the "new" old form of marijuana use growing in popularity}

Even though "dabbing" is often portrayed as a new trend by the popular media, its origins among American substance users can be easily traced back to the 1960s with other forms of extracts used well before that time. ${ }^{1}$ It is believed that soldiers in the Vietnam conflict would extract tetrahydrocannabinol (THC) into a liquid concentrate by using solvents such as acetone or petrol. These users would then either smear the product onto a rolling paper or saturate tobacco with the liquid concentrate. ${ }^{1}$ Another form of hashish oil called "smash" also made a brief appearance in 1967 in the United States. ${ }^{1}$

Today's amateur extracts are often created using a process that involves butane, hence the term "butane hash oil" (BHO), but regardless of the solvent, the result is a product potentially far more potent than flower cannabis., ${ }^{2,3}$ The emergence of medical and legal recreational marijuana in the United States has apparently facilitated increased interest in these extracts, referred to as BHO, dabs, oil, or by more specific terminology that describes the product's consistency (eg, shatter, honeycomb, crumble wax, budder, earwax). ${ }^{2,3}$ Generally, the term "dab" refers to an amount of BHO product associated 
with a single use while "dabbing" refers to the act of administering that product. ${ }^{4}$ Aiding in the newfound popularity of dabs are widespread cannabis community magazines, such as High Times, that present BHO concentrate as an easier method of utilizing once-wasted parts of the cannabis plant and claim BHO has superior pain relief properties. ${ }^{5}$ As a result, some even suggest that $\mathrm{BHO}$ products are now among the most commonly used illicit products in the United States. ${ }^{6}$

$\mathrm{BHO}$ is only one of several cannabis and cannabis-type products that have recently increased in availability in medical, retail, and illicit markets. The flowers of the female cannabis plant and other parts of the plant contain phytocannabinoids, including THC. These compounds act on the cannabinoid receptors in the brain and alter neurotransmitter release. Synthetic cannabinoids, which have also gained in popularity despite legal regulations, differ from these natural products derived from the cannabis plant but also act on cannabinoid receptors. ${ }^{7}$ Oils from the cannabis plant containing cannabinoids can be extracted in a number of ways and used to make high-THC concentration products that are inhaled (either by combustion or vaporization) or ingested. BHO is often made via a process that uses a solvent to draw THC and other cannabinoids from crude cannabis materials. In some instances, these techniques are selected so that the THC in parts of the plant not generally smoked can be recovered in a desirable form. ${ }^{3}$

Butane extraction involves passing liquid butane through raw vegetation. The hydrophobic compounds, such as THC, in the plant matter's trichomes readily dissolve in the butane and then pass through a filter with the butane. The butane is then either allowed to evaporate from the solution or it is actively purged with heat and/or a vacuum. ${ }^{8,9}$ The result, once again, is a product with a much higher THC concentration than flower cannabis ${ }^{2}$ referred to as dabs, shatter, honeycomb, oil, or wax depending on its consistency. This process can occur in a regulated commercial environment with modern closed-loop equipment or in a home garage with tools as simple as a steel tube, screen, and pyrex dish (referred to as amateur "blasting"). ${ }^{10}$

One underappreciated danger associated with the mass emergence of dabbing is related to its creation rather than its use. While safe, efficient, and well-regulated closed-loop systems are commercially utilized in recreational or medical states, dab production elsewhere often occurs in garages, tool sheds, and vacant homes. ${ }^{8}$ In these cases, the butane that is purged from the product can accumulate in a confined space and yield an explosion if ignited by a spark or static electricity. ${ }^{9}$ Explosions have been reported in numerous states including those in which dabs can be easily purchased..$^{911-13}$ It is perhaps the aspiration to utilize less desirable portions of the plant (ie, "trim") that motivates amateurs to attempt this process in legalization states (as BHO is already readily available at distributors at a price that is not restrictive); Colorado has seen an increase in BHO-related burns in the last several years ${ }^{9}$ (we define BHO-related burns broadly to include damage that results from accidents during the manufacturing process and from the blowtorch that is frequently used during administration). Regardless of the regulatory status of marijuana in a state, home "blasting" is considered in most jurisdictions to carry the legal consequences of operating a drug lab with strict penalties due to the risk of explosion. ${ }^{14}$ These explosions and burns represent a growing and underappreciated problem associated with dabbing that must be considered alongside any risks associated with use. ${ }^{6}$

The behavior generally referred to as "dabbing" typically involves heating an administration device, applying a marijuana extract so it vaporizes, and inhaling the vapors in one large dose. ${ }^{3,4}$ Many users choose an instrument referred to as an "oil rig" that is simply a water pipe with a hollow titanium, ceramic, or quartz "nail" or metal "swing" replacing the bowl. ${ }^{3}$ The nail is typically heated using a blowtorch prior to a "dab" of the extract being placed on it. When it is positioned on the hot nail the dab quickly vaporizes; the user inhales these vapors by drawing air though the other end of the pipe. The entire "dab" is intended to be inhaled in a single breath. ${ }^{15}$ There are several distinctions between this process and traditional flower cannabis use. Notably, individuals whose motor control may be affected by psychoactive substances are using torches rather than lighters, a large dose is administered in a single hit rather than a series of breaths, and a higher THC concentration product is being used. Alternatively, BHO can be administered using electronic heating devices akin to those used as e-cigarettes. ${ }^{8}$ With the exception of the dangers associated with blowtorch usage, the result is the same; a heated surface vaporizes the product which is then inhaled by the consumer (although dosage is more easily regulated through this method).

Within this review, we explore several aspects of dabbing and amateur $\mathrm{BHO}$ production to create a generalized review that may be beneficial to practitioners, researchers, and policymakers alike. This information is particularly critical to those in the field as amateur BHO extraction methods are oftentimes conducted in a manner that not only endangers the life of the user and their household, but also the first responders who may not currently have the knowledge or training to appropriately deal with $\mathrm{BHO}$ labs. As dabbing is gaining 
traction across the country, the paucity of detailed academic and empirical literature surrounding "blasting" techniques is troubling; this review also helps summarize extant literature and directs the research community towards pressing concerns. Further, as marijuana policy in the United States continues to evolve, those tasked with modifying regulations related to marijuana, generally, and extracts, specifically, may benefit from a comprehensive assessment of the BHO risk. Thus, this manuscript offers a summary of BHO use, amateur production techniques, and suggested safety protocols based on information that is lacking within the messages reaching the general public.

\section{Creating a review of $\mathrm{BHO}$ research}

In order to develop a detailed and complete picture of butane hash oil research, we utilized GoogleScholar database and the following search terms: "dabbing," "dabs," "BHO," "butane hash oil," and "honey oil." We reviewed all peer-reviewed articles that were relevant regardless of publication date; given that dabbing is newly popular, works prior to 2010 on the subject were scarce. The research team explored works cited within and cited by those pieces to ensure all relevant information was obtained. Generally, very few studies described dab creation or dab use. ${ }^{10}$ We identified 25 meaningful articles; however, the majority were case studies, reviews, qualitative in nature, or described potential trends in popularity using detached data (eg, Twitter posts or web searches). A quantitative assessment would be inappropriate given that only two studies have notably large samples (357 and 273, respectively). We found the studies generally described one of three aspects of use and thus we chose to summarize what is known about dabbing in the following sections focused on 1) $\mathrm{BHO}$ users (both recreational and medicinal); 2) BHO production; and 3) risks (both related to fire/explosions and legal risk). Given that our assessment suggested inaccurate information (defined as information inconsistent with peer-reviewed literature) was reaching users, we follow these sections with a summary of the type of information contained in media and video reports. These additional sections are intended to inform public health officials about misinformation that may be corrected through educational campaigns and increase overall safety.

\section{BHO users and amateur-produced forms of $\mathrm{BHO}$ Recreational $\mathrm{BHO}$ users}

The most reliable sources of recreational drug information in the United States are nationally representative studies with established protocols and forms of measurement. For example, Monitoring the Future (MTF) has surveyed high school students across the country to assess the prevalence and extent of substance use among adolescents for over 40 years. Unfortunately, a system of this size is slow to adapt. Common emerging substances have not been quickly added to MTF instrumentation. For example, synthetic cannabinoids were not added until 2011 and synthetic cathinone derivatives until 2012, perhaps after usage of both peaked. ${ }^{16,17}$ Similarly, studies such as the National Survey on Drug Use and Health and the Youth Risk Behavior Surveillance System were slow to include these new types of drug use, if at all. Other monitoring techniques have similar shortcomings: emergency medical data and poison control call logs provide insight into the rates of acute harm, but cannot attest to overall prevalence ${ }^{18}$ while metabolite detection in pooled human waste products ${ }^{19}$ requires an understanding of the substance's degradation process which may not be initially understood and cannot differentiate how a substance was administered (eg, flower cannabis vs marijuana extracts).

Perhaps the best indication of BHO prevalence comes from the most recent MTF study which showed, $11.9 \%$ of high school seniors, $9.8 \%$ of 10 th graders, and $4.0 \%$ of 8 th grades had used marijuana in a vaporizer at some point in their life. ${ }^{20}$ That being said, the study did not differentiate between concentrates created through different extraction processes so some of these users may have obtained or created products not made using butane. On the other hand, these figures could be an underestimate since dabs created through butane extraction may be inhaled using an "oil rig," pipe (mixed with traditional flower cannabis), or other methods. Given these potential shortcomings, we turn to non-representative samples that provide information about BHO use.

Outside of anecdotal evidence, popular media reports, and the aforementioned MTF study, very little is known at present about the characteristics of recreational BHO users (eg, “dabbers"), societal interest in dabbing, or the rate of harms associated with dabbing. However, a limited number of studies have addressed dabbing specifically. Loflin and Earleywine's ${ }^{15}$ evaluation of 357 habitual marijuana users indicates that users report no more problems as a result of dabbing than associated with flower cannabis use; however, their sample was non-random and largely comprised of heavy marijuana users. Multiple studies have reported psychoses following dab usage, ${ }^{21,22}$ another cardiotoxicity ${ }^{23}$ and yet another reported respiratory failure, ${ }^{24}$ but as these are case studies, the rate of this outcome is unknown. High dosages 
of cannabinoids can be associated with a variety of health risks (eg, increased risk of myocardial infarction in those with cardiovascular disease ${ }^{25}$ and chronic cognitive impairment, ${ }^{26}$ ) but it is unclear whether dabbers consume enough THC for these outcomes to be plausible. Since cannabinoids other than THC are also present in higher quantities in BHO, there may be a potential for increased therapeutic benefits - although in the few studies conducted on BHO users, it appears the primary factor for using $\mathrm{BHO}$ is the increased THC levels for recreational purposes. Miller et $\mathrm{al}^{10}$ interviewed a group of individuals under criminal justice supervision with a history of recreational dabbing and found these users preferred the effects of dabbing that they labeled as stronger and distinct from traditional flower cannabis. They also reported hoarding their supply and only using in isolation, behaviors not normally associated with marijuana. Meier $^{27}$ argued that symptoms of physical dependence were more common in BHO users than among those that only used traditional flower cannabis in the last year within a sample of 273 marijuana users.

Krauss et al's ${ }^{28}$ study suggests that dabbing repeatedly may be common and that young men are more likely to dab. Analysis of social media data suggest that dabbing is more frequently discussed in medical and legalized recreational states $^{29}$; whether this is a result of use being more common in those areas or users simply feeling more at ease posting about marijuana than in prohibition states is unknown. Daniulaityte et al's ${ }^{30,31}$ follow-up studies utilized an online convenience sample and suggest that concentrate use is more common within medical and recreational states. Their work also suggests males and those with lengthier marijuana use histories are more likely to use products like dabs. While Daniulaityte et $\mathrm{al}^{29}$ demonstrate variation in dabbing discussions via social media, their work fails to fully capture public interest and the rate at which curiosity about dabbing is changing. Similarly, Krauss et $\mathrm{al}^{28}$ describe user characteristics through unobtrusive measures, but do not report on the full social context of dabbing. Interest in $\mathrm{BHO}$ and in each form of $\mathrm{BHO}$ apparently varies regionally and by age, but there is no systematic data on $\mathrm{BHO}$ users and their age distribution; cannabis flower usage statistics may aid in creating a plausible picture of the profile of $\mathrm{BHO}$ users and its potential growth since Kilmer et $\mathrm{al}^{32}$ indicated that $40 \%$ of past-month cannabis users and $52 \%$ of daily and near-daily users reported dabbing. According to the 2016 National Survey on Drug Use and Health (NSDUH), the percentage of people 12 years or older, who self-identified as current marijuana users, has increased between 2002 and 2015 - approximately $6.5 \%$ of adolescents aged 12-17 are current marijuana users, as are $20.8 \%$ of young adults aged $18-25$ and $7.2 \%$ of individuals 26 years or older. This increased popularity of marijuana has been attributed to the emergence of recreational marijuana markets, successful therapeutic practices involving medical marijuana products, and changing norms around the acceptance of marijuana use and its potential danger. ${ }^{33}$

There are a few types of BHO that are repeatedly described in the available recreational cannabis literature. The two main types of hash-oil are wax and shatter. Wax BHO concentrates usually do not have a full crystalline structure; this is due to purposeful agitation by the user or due to some undesired disruption during the extraction process. The subcategories of wax concentrates include sugar crumbles, wax crumbles, and butter wax. Sugar crumbles have a crystallized surface. When disturbed, the texture is "crumbly" and easily falls apart. On the other hand, wax crumbles, are similar to sugar crumbles because they crumble apart easily but they maintain a smooth, slick surface. Finally, butter waxes are creamy and silky; of the different sub-categories of wax concentrates, butter wax is the most desirable or the "cream of the crop" of wax concentrates. ${ }^{34}$ Sub-categories of shatter concentrates vary from a thin, oily consistency to a brittle and glass-like structure. This is oftentimes dependent on a number of outside factors such as temperature, humidity, and production techniques. Shatter concentrates are typically differentiated by how translucent they are but that does not necessarily reflect their perceived quality among users. ${ }^{34}$ There are also emerging "solventless" methods of creating marijuana concentrates such as the "rosin-tech" method which essentially consists of the user applying continuous pressure and a moderate level of heat in order to create concentrates, rather than the inherently dangerous process of butane extraction. ${ }^{35}$

\section{The medicinal marijuana patient and concentrates like $\mathrm{BHO}$}

Concentrates appear to be popular among those with access to medical marijuana-medical marijuana patients even seem to use concentrates at a much higher rate than non-patient marijuana users. ${ }^{36}$ It is not known whether this differential is due to easier access to dabs or the belief that concentrates offer greater symptom relief with fewer drawbacks for individuals with ailments. Empirical studies in general suggest that vaporizing commercially produced concentrates does lessen the consumption of byproducts and lead to purer dosing $^{37}$; however, the lag time between administration and the onset of effects in patients is often associated with redosing 
and thus larger quantities consumed than anticipated. ${ }^{38}$ Higher dosing may not be desirable for pain management as efficacy appears greatest at moderate dosages ${ }^{39}$ and high dosing can carry risk for patients with other conditions. ${ }^{25}$ Further, as the demographics of medical marijuana patients skew older than recreational dabbers, there may be heightened risk of the high dose of THC in dabs interacting with preexisting conditions and other medications. Regardless, medical marijuana patients are likely less negatively affected by dabs as they have access to products manufactured using a well-regulated closed-loop system. Additionally, products intended for medicinal use may have lower levels of THC and higher levels of other cannabinoids associated with more therapeutic properties. We maintain that an underappreciated risk is associated with recreational users creating and consuming dabs made via an open system by an amateur without oversight of any regulatory body and in violation of the law.

\section{The hash oil production process}

Essentially, BHO products are potent marijuana concentrates that require the butane as part of a careful process of extracting THC from marijuana plant product. ${ }^{2,9}$ While commercial and at-home practices greatly differ, the general purpose is to dissolve the cannabinoids and terpenes in butane in order to separate them from the solid plant material and yield a highly potent THC concentrate. ${ }^{8}$ Tetrahydrocannobinol (THC) and other cannabinoids fill trichomes, which appear to the naked eye as tiny, clear white or amber mushrooms erupting from the leaf of the cannabis plant. In addition to their location on the more potent portions of the plant, trichomes also appear in areas thought of as too low in THC concentration for traditional marijuana smoking. ${ }^{34}$ The oils in these trichomes are hydrophobic, meaning they do not dissolve in water the way sugar or salt do, but they dissolve in solvents such as butane or isopropyl alcohol. ${ }^{8}$ Thus, exposure to a solvent such as butane can help separate the hydrophobic compounds in the trichomes from solid plant matter. There are also other, increasingly less popular, amateur methods of extracting THC from the cannabis plant including using solvents such as isopropyl alcohol, $\mathrm{CO}_{2}$ (also used commercially), and other chemical-based solvent extractions, ${ }^{2}$ but in the marijuana community, it appears that butane is perceived as the more efficient alternative for amateur production. ${ }^{6}$

The process of producing BHO involves two-steps, the first of which includes packing a "blasting" tube with marijuana. Available research on amateur BHO production techniques states that users will place dry marijuana material in a tube that is usually made of steel or glass and sealed on one end with some type of filter (coffee filters, a portion of a window screen, etc.). The tube is packed tightly with marijuana product and liquid butane is poured, generally from a small user-grade butane canister, into the open end of the tube. ${ }^{3}$ The butane dissolves the trichomes as it passes through the tube, removing the hydrophobic psychoactive compounds from the plant material. The liquid butane extract passes through the filtered end of the tube, leaving a solid waste-product in the tube that is either discarded or used in edibles and other low-potency products.

The second step of the process is referred to as purging. This involves attempting to separate the butane from the resulting material in order to yield a high THC product with minimal butane. Heating plates, vacuum ovens, shaker plates, spatulas, and other devices may be used (to differing degrees of risk) to assist butane vapors in leaving the substance. It is during the process of "extracting" the remnants of the butane from the final product when issues such as explosions and flash fires most frequently occur. ${ }^{40}$ Butane is a flammable gas that is heavier than air. It has a lower explosion limit of $1.6 \%$ and an upper explosion limit of $8.75 \%$, meaning that the air becomes explosive when it is being mixed with only $1.6 \%$ butane. The butane that escapes from the extracted substance as a vapor eventually pools on the lowest surface available and flows until it finds an outlet that allows it to dissipate, rather than "off-gassing" as is the nature of other solvents. These vapor pools are easily ignited by a spark, flame, or static electricity and are the cause of the majority of the harms associated with butane hash oil production.

Commercial production of extracts in medicinal and recreational states generally does not carry the same risk of fire as it utilizes a closed-loop system that recycles the solvent (whereas the process described above is considered an open system as the butane escapes). Within a closed-loop system, a machine recovers and recycles the butane; it is not released into an area in which it may be inadvertently ignited. ${ }^{5}$ The closed-loop system of extraction is utilized by retail manufacturers of $\mathrm{BHO}$ concentrates and is clearly the safer of the two methods. ${ }^{41}$ Both forms of extraction methods may yield a host of BHO concentrates (crumble, wax, shatter, etc.), each varying in their use and perceived quality. ${ }^{42}$

While the butane that is purged during open system production is worrisome due to fire risk, a portion of butane used likely remains within the product - the amount depending on a number of factors both related to the skill of the producer and environmental conditions such as temperature and humidity. Users of amateur-produced BHO likely inhale this butane and other impurities along with the vaporized THC. Butane 
inhalation carries numerous risks beyond convulsions and hallucinations, including cardiac damage/arrhythmias, ${ }^{43}$ organ failure, ${ }^{44}$ respiratory depression, vagal inhibition, and anoxia. ${ }^{45}$ While dabbers likely inhale less butane than those attempting to get high on a solvent alone, ${ }^{46}$ the amount is not negligible and should not be disregarded in the absence of acute issues; solvent inhalation can be associated with chronic problems such as cardiomyopathy, renal damage, liver damage, and a variety of psychiatric syndromes. ${ }^{47}$ These concerns are mitigated when consumers purchase products from regulated manufacturers in recreational and medicinal states which use closed-loop processes that more effectively recover solvents, but the interest in and availability of dabs suggest that illegal amateur open system production is rampant in both prohibition and recreational marijuana states.

The popularity of at-home BHO labs appears to be rapidly increasing due to an array of reasons including but not limited to curiosity, the perceived ease of production, ${ }^{6}$ and increased potential opportunities for financial gain. ${ }^{9}$ Unfortunately, there are no systematic studies which address the characteristics of individuals who chose to produce $\mathrm{BHO}$ in the home; however, it is likely that amateur producers are marijuana users with access to cannabis plant material and a desire to salvage parts of the plant product or "trim" that had once gone to waste. For less than 100 dollars, many users are able to purchase the equipment necessary for an at-home $\mathrm{BHO} \mathrm{lab}^{2}$ and utilize both high-THC parts of the plant and trim to produce a powerful product. ${ }^{8} \mathrm{BHO}$ concentrates report particularly high concentrations of THC in the final product. Different reports state amateur hash oil products to contain THC concentration at anywhere up to 50\% (with commercial products reaching even higher concentrations), compared to the historical potency of flower cannabis of about $4 \%-8 \%$ and high end recreational and medical flower cannabis approaching 30\%. ${ }^{9,48}$ Repeat marijuana users report that $\mathrm{BHO}$ concentrates yield a different high - one that requires a reduced number of inhalations in order to achieve the desired effect. ${ }^{2}$ Users are also praising $\mathrm{BHO}$ products as a healthier, more efficient alternative to other marijuana products, going as far as to claim the "blasting" process kills bacteria and other pathogens found in the original plant material ${ }^{8}$ and that $\mathrm{BHO}$ provides intense pain relief properties beyond that of typical marijuana. ${ }^{5}$

\section{Detailing the dangers The rising rates of flash fires/explosions}

Despite the attempts of recreational and medicinal marijuana states to regulate the at-home practices of individuals, there appears to be a marked rise in hydrocarbon and flash burns associated with $\mathrm{BHO}$ production in these areas. ${ }^{42}$ Due to the volatile nature of using a liquid-gas such as butane in an illegal extraction process, $\mathrm{BHO}$ production is inherently unsafe and has the potential to yield catastrophic results. ${ }^{2}$ Bell et al, ${ }^{9}$ using a cross-sectional study utilizing data from the American Burn Association's National Burn Repository, examined the prevalence of hydrocarbon burns labeled by the University of Colorado Hospital Burn Center as having occurred due to "explosion of gases" and "ignition of highly flammable material." Bell et al's" study concluded that the legalization of marijuana in Colorado was associated with the unexpected rise of hydrocarbon flash burns occurring due to activities associated with $\mathrm{BHO}$ production.

A similar study conducted in California identified eight BHO-related burn incidents that were managed at the burn unit of the University of California, Davis Medical Center between September 2011 and September 2012. In a retrospective analysis, Jensen et $\mathrm{al}^{6}$ analyzed these burn incidents related to hash-oil production noting that flash burns that were sustained due to the explosion of gases pooling during the blasting process and the victim's clothing subsequently catching fire. The study indicates that there appeared to be an increase in the BHO production performed by small groups of people, rather than by individuals, thus, increasing the number of burn victims admitted to the hospital and overtaxing the resources of the burn unit. Jensen et $\mathrm{al}^{6}$ stated that there appears to be a focus in the marijuana community on the alleged potential benefits of hash-oil and a corresponding lack of "risk awareness" regarding the BHO production process. The study concluded that increased awareness on the dangers of $\mathrm{BHO}$ production could potentially prevent future burn incidents.

While both these studies indicate amateur BHO extraction can be tied to burns and flash fires, an argument also bolstered by police reports, fire departments, and the media, ${ }^{40}$ any summary of extraction-related fires is likely to underestimate their prevalence. As the blasting involves a federally scheduled substance which is also scheduled in numerous states, victims are unlikely to report the source of their burns unless forced to by circumstance. Put simply, those able to seek care without utilizing emergency services are unlikely to admit that the source of their burn was related to drug extraction. Even in circumstances where emergency personnel are called to respond to a fire, this incident may not be identified as butane extraction related since training on "blasting" has been limited in the past and the tools used in the process appear to be routine household items. An increasing number 
of fires in garages, workshops, and transient housing locations may be the result of $\mathrm{BHO}$ production and justifies increased scrutiny on these types of fires so that their prevalence can be adequately assessed and harm reduction approaches efficiently implemented.

Recognition of these incidents is likely improving. Although only a few emergency responders have received training on how to recognize and respond to BHO-related incidents, training for law enforcement and fire fighters has become available. For example, in response to several incidents in 2013 the Aurora Fire Department in Colorado had their Fire and Explosive Investigation Bureau trained on the manufacture, use, and hazards of BHO ${ }^{49}$ For police agencies, a 3-hour online course on Butane Hash Oil Investigations is available from Law Enforcement Learning which provides information on how to recognize $\mathrm{BHO}$ labs and how to stay safe while investigating cases.

\section{Legal risks tied to $\mathrm{BHO}$ production}

The increasing number of hydrocarbon flash burns associated with at-home $\mathrm{BHO}$ production has forced many medical and recreational states alike to utilize the criminal justice system as a deterrent for production of butane-extracts at home. ${ }^{41}$ Most jurisdictions, when prosecuting, utilize existing broader legislation for penalizing amateur BHO production as laws specific to BHO do not exist. State laws generally allow for the prosecution of individuals who convert, process, or prepare recreationally used drugs through extraction or synthesis - in addition to any penalties associated with possession. ${ }^{14}$ These statutes do not generally apply to alcohol, but marijuana and controlled substances cannot be altered without the "cook" potentially being charged with violating additional state laws. This likely would affect individuals that only assisted with one aspect of the production process (using the butane or purging the butane) as both alter the substance. Put another way, while laws vary between states, most characterize the in-home butane extracting process to qualify as the operation of a drug lab. In such cases, blasting would carry penalties similar to the production of methamphetamine regardless of the legality of marijuana in that state. ${ }^{10,14,41}$ In fact, anecdotal evidence, media coverage of BHO fires, and preliminary studies of BHO burns suggest that they are more of a problem in states with recreational or medicinal marijuana ${ }^{50}$ leading those jurisdictions to develop stringent penalties in an attempt to deter dangerous production techniques (penalties vary between states; California statutes allow for 3-year sentences); however, we caution that BHO-related fires may be equally common in prohibition states and simply be less frequently identified as BHO fires due to the more open dialog about marijuana in general in recreational and medicinal states.

Many of the laws implemented are modeled on the regulations of California, Colorado, and Washington. Washington passed the "Cannabis Patient Protection Act" (CPPA) which prohibited medical marijuana manufacturers from using butane gas to manufacture extracts. According to Senate Bill 5052, licensed recreational processors are still allowed to use butane to process $\mathrm{BHO}$ at a state-certified facility. ${ }^{51}$ It was specified that the individuals operating the system must be licensed by the state's Liquor and Cannabis Control Board. Recreational manufacturers must use closed-loops systems. ${ }^{52}$ As outlined in Washington's Marijuana Processes License Extraction Requirements Act of 2018, commercial manufacturers are largely concerned with maintaining low to minimal toxicity in the solvents utilized. Commercial manufacturers are also concerned with ensuring closed-loop extraction methods properly recover solvents, maintain the necessary ventilation to ensure proper disposal of butane in the case of faulty recovery processes, and control access to potential flammable sources present.

In Colorado, much like Washington, it is emphasized that state-licensed manufacturers must produce BHO concentrates utilizing commercial-grade, closed-loop systems. Colorado also requires that the individuals operating the closed-loop system be certified hygienists and the systems be inspected by an engineer. The individuals operating the systems must also undergo criminal background checks and extensive safety training. While Colorado and Washington have similar regulations, Colorado is surprisingly much stricter than Washington. Finally, California allows medical marijuana distributors to possess and sell BHO products but not to produce. In fact, California is one of the growing number of states that are attempting to crack down on the rise of BHO labs in recreational/medicinal states by prosecuting BHO labs in the same manner as methamphetamine labs. ${ }^{2}$ State administrative agencies, such as the Washington State Liquor and Cannabis Board (WSLCB), oversee and upkeep state-level closed-loop extraction guidelines. Guidelines are presented and created by licensed engineers accredited by the American Society of Mechanical Engineers (ASME), American National Standards Institute (ANSI), Underwriter Laboratories (UL), or the American Society for Testing and Materials (ASTM). The set regulations must meet required fire, safety, and building code requirements as specified by the National Fire Protection Association (NFPA), International Building Code (IBC), and International Fire Codes (IFC). ${ }^{52}$ 
Despite the legal strides a number of states have taken to ensure the safety of their communities, the regulation of BHO has done very little to control the rise of BHO-related explosions and fire incidents. ${ }^{41}$ The gradual decriminalization of marijuana across the United States has unexpectedly resulted in a rise in hydrocarbon flash burns associated with illegal, at-home butane BHO production. ${ }^{9}$ The criminalization of at-home $\mathrm{BHO}$ production has subsequently forced producers underground - increasing the likelihood that they utilize poorly ventilated, indoor rooms where the risks of gases collecting and the ignition of volatile substances are greatly increased. ${ }^{6}$

\section{What information related to $\mathrm{BHO}$ use is currently reaching the population?}

As the population draws information from the media and may choose to base their behavior on that information, it becomes important to identify what information reaches potential $\mathrm{BHO}$ users in order to direct public health campaigns or other response. Therefore, we assessed the quantity and content of print media coverage within a sample of 20 high-readership newspapers selected through a stratified sampling technique. The United States was divided into five regions and four papers were randomly selected from each of these regions. Only papers credited by the Audit Bureau of Circulation as having one of the largest 100 readerships in the US were included in the sampling frame. After this process, another four papers were added to ensure key local locations (eg, Colorado) were represented as the randomization process excluded the locations. All media articles published between January 1, 2012 and February 18, 2015 in one of these sources and including one of eight key terms were evaluated for inclusion ("butane hash oil," "BHO," "dabs," "honey oil," "dabbing," "budder," "hash oil," and "dab wax"). This search generated 185 newspaper articles, each of which was obtained through LexisNexis database. An initial review eliminated 117 of these articles that were focused on some other issue (eg, a number of cooking articles were eliminated as they contained the terms "honey" and "oil," but had nothing to do with cannabis use). The exclusion of these non-relevant articles yielded a sample of 68 qualified articles, each of which was reviewed and assessed by two researchers according to a predetermined coding scheme. Agreement on coding was high ( $88.5 \%$ of items) indicating good reliability between coders; Cohen's kappa was calculated to be 0.572 which is interpreted as there being moderate/substantial agreement. ${ }^{53}$ In instances where there was disagreement between coders, a score was selected by a third member of the research team.
Roughly one-third (32.5\%) of the sampled reports were focused specifically on dabbing or BHO; half were written on marijuana more generally and addressed the issue of dabbing as part of broader content. By far, the most common primary theme throughout the articles was that of legality (26.5\%) which was mentioned, but not the primary focus, in another $16.2 \%$ of articles. Other common themes were marijuana and dabbing's association with crime (mentioned in $47.1 \%$ of articles, but only the primary theme of $13.3 \%$ ) and the business of marijuana distribution (33.8\% total, $11.8 \%$ primary theme). There was not much consistency in the terms used to refer to dabs; terms like "dabs," "honey oil," "crumble," "shatter," and "budder" were all used but none in more than $12 \%$ of the articles. Similarly, paraphernalia was mentioned in several articles, but no term appeared in more than $11 \%$ of the articles; such ambiguity displays the lack of consistency between terms. Users were not described often (41.2\%), but every article noting users described at least one male; $8.8 \%$ also referred to at least one female user. Articles rarely remarked on the race of users/potential users (10.3\%) and none linked dabbing to African Americans. Of the articles, nearly two-thirds (66.2\%) directly stated or implied that the trajectory of marijuana use and dabbing is increasing.

Cumulatively, the printed press articles portrayed $\mathrm{BHO}$ as harmful (55.9\%) with more than half of those characterizing dabbing as being associated with severe harms. Alternatively $23.5 \%$ classified $\mathrm{BHO}$ as having beneficial effects in the context of medicinal use. The majority of articles did not address the quality of the dabbing high relative to marijuana. Of those that did, evaluations were mixed with $19.1 \%$ describing it as less desirable and $16.2 \%$ describing it as more desirable. An analysis of reporting by region of the country revealed two key differences; a larger portion of articles written in the west described dabbing as increasing in popularity (79.5\%) and a discussion of the commercial distribution of dabs was more often the primary theme (20.5\%). It appears that coverage in legalization and decriminalization states generally mirror that of probation and medical states except that coverage in those states frequently implied or directly argued that marijuana and $\mathrm{BHO}$ use were increasing $(86.1 \%$ of the articles in that region vs $43.8 \%$ of the articles published elsewhere).

Surprisingly absent from the majority of these articles was a candid discussion of fire risks associated with at-home production. Only $19.1 \%$ referenced the issue in any way and these articles all appeared in a small group of publications suggesting that the readership in other areas of the country is exposed to BHO-related content in the absence of appropriate indications of the risk of fire and explosions. For this 
reason, it is recommended that campaigns responding to the emergence of $\mathrm{BHO}$ production focus on the risk associated with allowing butane to pool in an enclosed space. We caution against overly sensationalized messages, but suggest that it will be effective to recommend harm reduction practices such as increasing ventilation when "blasting," being aware of ignition sources, avoiding clothing that may create static, purchasing commercially produced dabs, or abstaining from extracts as a whole.

Since traditional media may be less frequently accessed by potential BHO users and amateur producers, we also examined the quality, accuracy, and content of videos related to blasting posted on YouTube to determine what (mis)information might be reaching the public. Using the search terms "BHO blasting," "how to make shatter," and "how to make honey oil," we identified the first 30 videos appearing in the search results that demonstrated amateur production. Videos appearing to include minors, of particularly poor video quality, and in languages other than English were excluded. The lead author viewed each of these videos twice, recording notes using a predetermined scoresheet. This process revealed that higher perceived video quality seemed to correlate with the mention of safety precautions and three distinct concerning themes: "safety last," omission of contaminant concerns, and overlooking legality.

- Safety last. The overwhelming majority of videos either fail to mention or trivialize the threat of fire. Considering the potential for disaster if the user commits a misstep during the blasting and purging processes, it is vital to note that the majority of the videos do not contain information about potential fire or explosion hazards. Rather, even the mention of the potential hazards associated with $\mathrm{BHO}$ extraction seems to be taken as a joke. Narrators joked about reported flash fires and explosions stating that such incidents only served to give other BHO users a "bad name." At best, there appears to be a silent acknowledgement of the potential dangers of at-home, amateur extraction methods - it even seems if the narrators generally have the expectation that the viewer is already appropriately informed of the risks and thus see no need to inform viewers.

- Ignoring contaminants. The health and wellness risks of BHO users appears to take a back seat in the online discussions of various $\mathrm{BHO}$ production techniques to positive outcomes such as analgesia. Though Raber et al's ${ }^{2}$ study suggests that over $80 \%$ of samples are contaminated with residual solvent and pesticides not a single video discussed the potential, or likely, solvent contamination in the final product which as discussed previously, carries health risk.

- Disregarding legality. Of the 30 videos examined, only two explicitly stated that the viewer must act upon their own discretion and become knowledgeable with the law of their state and specific county. These two videos also presented a compelling safety warning to the viewer. The remainder led the viewer to make inferences about legality that may be inaccurate given that states with recreational and/or medicinal marijuana still criminalize amateur $\mathrm{BHO}$ production.

\section{Conclusions}

Despite the potential consequences of illicit BHO production, at-home production rates appear to be increasing. There continues to be a lack of detailed literature for researchers and professionals to utilize when creating a response to this issue. The deficit of "risk awareness" is particularly affecting first responders' ability to recognize a BHO lab when they see it and mitigate situational dangers. Perhaps equally importantly, how those labs function and what practices and techniques are being shared between amateur BHO users is inadequately understood among public health officials. This paper aimed to summarize the existing pool of knowledge on the extraction techniques used by amateur BHO users for the specific purpose of assisting readers with recognizing some of the themes surrounding the culture of $\mathrm{BHO}$ production. In the end, there is more unknown than known about dabbing and blasting in the United States - research is sorely needed on user characteristics, availability, distribution, rates of amateur production, acute and chronic harms, and the effect of legal sanctions on production and use.

We stress above all else that the risks of amateur BHO production seem to outweigh concerns about the substance's psychoactive effects or distribution, that every effort should be taken to inform potential amateur producers about the fire risk associated with allowing butane to collect in an enclosed space, and mechanisms must be put into place to mitigate risk as much as possible. Acknowledging that the eradication of interest in marijuana concentrates is unlikely, we recommend an informative harm reduction approach that centers around safety. A multifaceted approach is needed that provides information and training for emergency responders to recognize BHO lab indicators and their associated hazards to improve responses to these incidents and reduce the chance of harm to personnel along with campaigns to provide potential amateur BHO manufacturers with information 
about the dangers involved with blasting. As the extraction process is simple, users may assume that risks are limited (an assessment perhaps further facilitated by the casual nature "how-to" BHO production videos on YouTube), but this is inaccurate and the misperception must be corrected. We urge officials to recommend against amateur BHO production in a way that highlights the danger and instills caution among those who disregard that advice and choose to engage in blasting anyway.

Reaching individuals that may produce $\mathrm{BHO}$ in their homes is challenging in that potential blasters are a hidden population. Further, there is limited utility in educating individuals or the public only after an accident. As such, it is more reasonable to create broad sweeping messages emphasizing the risk associated with butane extraction and mechanisms that may lessen risk. Focus may be directed at age groups more likely to utilize concentrates, however this might be shortsighted as there is no information confirming the age distribution of blasting mirrors that of dab consumption. We do suggest that any harm reduction public health campaign designed to minimize damages linked to blasting also consider spreading accurate information via the same channels that are spreading misinformation. As many may be learning unsafe practices through YouTube, there is utility in providing safer advice through the same platform. Further, marijuana enthusiast groups and publications can be of assistance in warning of the dangers of amateur BHO production. For example, an article published on Merry Jane, a cannabis-focused media site, warns of the dangers associated with amateur BHO production. ${ }^{54}$ The article also warns consumers to pay close attention to the labels and whether they include purity information and advocates that consumers demand "more thorough standards for BHO and other extracted products at your local dispensary." Although this approach is not possible in prohibition states, a combined effort of public health and cannabis enthusiasts could lead to a general increased awareness of the dangers associated with amateur BHO manufacturing and from contaminated products. While these messages may not deter all individuals, they may very well carry more weight when delivered by law enforcement paired with pro-cannabis groups and eventually mitigate some risk.

\section{Acknowledgments}

The authors would like to thank research assistants Theodore Cantor and Devin Patel for assistance with data collection. No specific funding was utilized for this project.

\section{Disclosure}

The authors report no conflicts of interest in this work.

\section{References}

1. Booth M. Cannabis: A History: New York: Picador 2005. ebook Macmillan; 2015.

2. Raber JC, Elzinga S, Kaplan C. Understanding dabs: contamination concerns of cannabis concentrates and cannabinoid transfer during the act of dabbing. J Toxicol Sci. 2015;40(6):797-803.

3. Stogner JM, Miller BL. Assessing the dangers of "dabbing": mere marijuana or harmful new trend? Pediatrics. 2015;136(1):1-3.

4. Stogner JM, Miller BL. The dabbing dilemma: a call for research on butane hash oil and other alternate forms of cannabis use. Subst Abus. 2015;36(4):393-395.

5. Black B. What is hash oil? January 2, 2015. Available from: https:// hightimes.com/culture/to-dab-or-not-to-dab/. Accessed October 11, 2018.

6. Jensen G, Bertelotti R, Greenhalgh D, Palmieri T, Maguina P. Honey oil burns: a growing problem. J Burn Care Res. 2015;36(2):e34-e37.

7. Stogner JM, Miller BL. A spicy kind of high: a profile of synthetic cannabinoid users. J Subst Use. 2014;19(1-2):199-205.

8. Rosenthal E, Downs D. Beyond Buds: Marijuana Extracts - Hash, Vaping, Dabbing, Edibles and Medicine. Piedmont, CA: Quick American; 2014.

9. Bell C, Slim J, Flaten HK, Lindberg G, Arek W, Monte AA. Butane hash oil burns associated with marijuana liberalization in Colorado. J Med Toxicol. 2015;11(4):422-425.

10. Miller BL, Stogner JM, Miller JM. Exploring butane hash oil use: a research note. J Psychoactive Drugs. 2016;48(1):44-49.

11. Porter CJ, Armstrong JR. Burns from illegal drug manufacture: case series and management. J Burn Care Rehabil. 2004;25(3):314-318.

12. Fang S. New marijuana trend sends tokers to burn units. AlJazeera America.com. Available from: http://america.aljazeera.com/watch/ shows/america-tonight/articles/2015/1/2/thc-burn-victims.html. Accessed February 6, 2015.

13. Schneberk T, Valenzuela RG, Sterling G, Mallon WK. Prehospital ramifications of butane hash oil synthesis and use. J Emerg Medical Services. September 4, 2015. Available from: https://www.jems.com/ articles/print/volume-40/issue-9/features/prehospital-ramifications-ofbutane-hash-oil-synthesis-and-use.html. Accessed October 11, 2018.

14. People v. Bergen. 166 Cal. App. 4th 161. 2008. Available from: https://scholar.google.com/scholar_case?case $=13508467635663325$ $232 \& \mathrm{q}=$ People $+\mathrm{v} .+$ Bergen $.+166+$ Cal. + App $.+4 \mathrm{th}+161 .+2008 \& \mathrm{hl}=\mathrm{en}$ \&as_sdt=6,31\&as_vis $=1$. Accessed October 11, 2018.

15. Loflin M, Earleywine M. A new method of cannabis ingestion: the dangers of dabs? Addict Behav. 2014;39(10):1430-1433.

16. Johnston LD, O'Malley PM, Miech RA, Bachman JG, Schulenberg JE. Monitoring the Future National Survey Results on Drug Use: 1975-2015: Overview, Key Findings on Adolescent Drug Use. Ann Arbor, MI: Institute for Social Research, The University of Michigan; 2016.

17. Maxwell JC. Psychoactive substances - some new, some old: a scan of the situation in the US. Drug Alcohol Depend. 2014;134:71-77.

18. Substance Abuse and Mental Health Services Administration; 2013. DAWN (Drug Abuse Warning Network). National Estimates of Drugrelated Emergency Department Visits. Vol. D-39. Rockville, MD: HHS publication SMA 13-4760, DAWN series; 2014.

19. Archer JR, Hudson S, Wood DM, Dargan PI. Analysis of urine from pooled urinals - a novel method for the detection of novel psychoactive substances. Curr Drug Abuse Rev. 2013;6(2):86-90.

20. Miech RA, Schulenberg JE, Johnston LD, Bachman JG, O’Malley PM, Patrick ME. National press release: "National Adolescent Drug Trends in 2017: Findings Released." Monitoring the Future: Ann Arbor, MI; December 14, 2017. Available from: http://www.monitoringthefuture. org/pressreleases/17drugpr.pdf. Accessed October 10, 2018. 
21. Pierre JM, Gandal M, Son M. Cannabis-induced psychosis associated with high potency "wax dabs". Schizophr Res. 2016;172(1-3): 211-212.

22. Keller CJ, Chen EC, Brodsky K, Yoon JH. A case of butane hash oil (marijuana wax)-induced psychosis. Subst Abus. 2016;37(3): 384-386.

23. Rickner SS, Cao D, Kleinschmidt K, Fleming S. A little "dab" will do ya' in: a case report of neuro-and cardiotoxicity following use of cannabis concentrates. Clin Toxicol. 2017;55(9):1011-1013.

24. Stahlmann CG, McMahon M, Bhatt NA, Perkins MP, Philip AI. Dabble with danger: a case of severe respiratory failure following inhalation of butane hash oil. American Thoracic Society 2015 International Conference: Toxic Ingestions and Exposures. 2015;C51:A4596-A4596.

25. Mittleman MA, Lewis RA, Maclure M, Sherwood JB, Muller JE. Triggering myocardial infarction by marijuana. Circulation. 2001;103(23):2805-2809.

26. Solowij N. Cannabis and Cognitive Functioning. Cambridge, UK: Cambridge University Press; 1998.

27. Meier MH. Associations between butane hash oil use and cannabisrelated problems. Drug Alcohol Depend. 2017;179:25-31.

28. Krauss MJ, Sowles SJ, Mylvaganam S, Zewdie K, Bierut LJ, CavazosRehg PA. Displays of dabbing marijuana extracts on YouTube. Drug Alcohol Depend. 2015;155:45-51.

29. Daniulaityte R, Nahhas RW, Wijeratne S, et al. "Time for dabs": analyzing Twitter data on marijuana concentrates across the U.S. Drug Alcohol Depend. 2015;155:307-311.

30. Daniulaityte R, Lamy FR, Barratt M, et al. Characterizing marijuana concentrate users: a web-based survey. Drug Alcohol Depend. 2017;178:399-407.

31. Daniulaityte R, Zatreh MY, Lamy FR, et al. A Twitter-based survey on marijuana concentrate use. Drug Alcohol Depend. 2018;187: $155-159$

32. Kilmer B, Caulkins JP, Midgette G, Dahlkemper L, Maccoun RJ, Liccardo PR. Before the Grand Opening: Measuring Washington State's Marijuana Market in the Last Year Before Legalized Commercial Sales. Washington, DC: Rand Corporation; 2013.

33. Kerr WC, Lui C, Ye Y. Trends and age, period and cohort effects for marijuana use prevalence in the 1984-2015 US National Alcohol Surveys. Addiction. 2018;113(3):473-481.

34. MacLeod K. Types of BHO concentrates: wax, sugar, budder, crumbles, shatter, live resin - cannbasics \#6. [Ruffhouse Studios]. January 6, 2016. Available from: https://www.youtube.com/watch?v=zOmu0TEAPG4. Accessed October 11, 2018.

35. Lamy FR, Daniulaityte R, Zatreh M, et al. "You got to love rosin: solventless dabs, pure, clean, natural medicine." Exploring Twitter data on emerging trends in Rosin Tech marijuana concentrates. Drug Alcohol Depend. 2018;183:248-252.

36. Lankenau SE, Fedorova EV, Reed M, Schrager SM, Iverson E, Wong CF. Marijuana practices and patterns of use among young adult medical marijuana patients and non-patient marijuana users. Drug Alcohol Depend. 2017;170:181-188.
37. Russell C, Rueda S, Room R, Tyndall M, Fischer B. Routes of administration for cannabis use - basic prevalence and related health outcomes: a scoping review and synthesis. Int J Drug Policy. 2018;52:87-96.

38. Earleywine M, van Dam NT. Case studies in cannabis vaporization. Addict Res Theory. 2010;18(3):243-249.

39. Holdcroft A, Maze M, Doré C, Tebbs S, Thompson S. A multicenter dose-escalation study of the analgesic and adverse effects of an oral cannabis extract (Cannador) for postoperative pain management. Anesthesiology. 2006;104(5):1040-1046.

40. Long P. Hash oil extraction hazards: Safety for first responders. (Training Materials). Rocky Mountain Police Department; 2013.

41. Hudak J. Colorado's rollout of legal marijuana is succeeding. Case West Reserve Law Rev. 2015;65(3).

42. Monte AA, Zane RD, Heard KJ. The implications of marijuana legalization in Colorado. JAMA. 2015;313(3):241-242.

43. Novosel I, Kovačić Z, Gusić S, et al. Immunohistochemical detection of early myocardial damage in two sudden deaths due to intentional butane inhalation. Two case reports with review of literature. J Forensic Leg Med. 2011;18(3):125-131.

44. Rieder-Scharinger J, Peer R, Rabl W, Hasibeder W, Schobersberger W. Multiple organ failure following inhalation of butane gas: a case report. Wien Klin Wochenschr. 2000;112(24):1049-1052.

45. Sironi L, Amadasi A, Zoja R. Recreational inhalation of butane and propane in adolescents: two forensic cases of accidental death. Forensic Sci Int. 2016;266:e52-e58.

46. Howard MO, Jenson JM. Inhalant use among antisocial youth: prevalence and correlates. Addict Behav. 1999;24(1):59-74.

47. Williams DR, Cole SJ. Ventricular fibrillation following butane gas inhalation. Resuscitation. 1998;37(1):43-45.

48. Khey DN, Stogner JM, Miller BL. Emerging Trends in Drug Use and Distribution. New York: Springer; 2014.

49. Klein S. Butane hash oil manufacturing: it's a fire service problem, too. Fire Engineering. March 1, 2016. Available from: https://www. fireengineering.com/articles/print/volume-169/issue-3/fdic-preview/ butane-hash-oil-manufacturing-it-s-a-fire-service-problem-too.html. Accessed October 10, 2018.

50. Romanowski KS, Barsun A, Kwan P, et al. Butane hash oil burns: a 7-year perspective on a growing problem. J Burn Care Res. 2017;38(1): e165-e171.

51. Cannabis Patient Protection Act, U.S.C. 2016; $\$ 5052$. Available from: http://lawfilesext.leg.wa.gov/biennium/2015-16/Pdf/Bills/Senate\%20 Bills/5052.pdf. Accessed October 11, 2018.

52. Marijuana Processes License Extraction Requirements. W.A.C 2018:§314-55-104. Available from: http://apps.leg.wa.gov/wac/default. aspx?cite=314-55-104. Accessed October 11, 2018.

53. Landis JR, Koch GG. The measurement of observer agreement for categorical data. Biometrics. 1977;33(1):159-174.

54. Stetter R. The truth about butane and dabbing safety: scientists are setting the record straight about butane solvents. Merry Jane. September 13, 2016. Available from: https://merryjane.com/health/butane-dabbingsafety. Accessed October 10, 2018.
Substance Abuse and Rehabilitation

\section{Publish your work in this journal}

Substance Abuse and Rehabilitation is an international, peer-reviewed, open access journal publishing original research, case reports, editorials, reviews and commentaries on all areas of addiction and substance abuse and options for treatment and rehabilitation. The manuscript management system is completely online and includes a very quick and fair

\section{Dovepress}

peer-review system. Visit http://www.dovepress.com/testimonials.php to read real quotes from published authors. 